\title{
STRUKTUR KALIMAT DALAM TEKS ANEKDOT PADA BUKU TEKS SMA KELAS X
}

\author{
Rizki Sutiyani, Supadi, dan Marina Siti Sugiyati \\ Program Studi Pendidikan Bahasa Indonesia \\ Jurusan Pendidikan Bahasa dan Seni \\ FKIP Universitas Bengkulu \\ rizkisutiyani@gmail.com
}

\begin{abstract}
Abstrak
Tujuan dari penelitian ini untuk mendeskripsikan struktur kalimat dalam teks anekdot pada buku teks SMA kelas X (bagian abstraksi, orientasi, krisis, reaksi, dan koda) yang dikaji dari segi fungsi, kategori, dan peran setiap unsur kalimat. Penelitian ini merupakan penelitian deskriptif kualitatif. Data dalam penelitian ini adalah kalimat-kalimat dalam teks anekdot yang bersumber dari buku teks SMA kelas $X$. Teknik pengumpulan data pada penelitian ini menggunakan teknik catat. Data dianalisis dengan menggunakan teknik permutasi dan teknik parafrase. Hasil penelitian ini yaitu dari enam teks anekdot, hanya satu teks yang memiliki struktur teks anekdot lengkap. Lima teks lain memiliki struktur tidak lengkap. Selain itu, analasis kalimat berdasarkan fungsi, kategori, dan peran pada bagian abstraksi, orientasi, krisis, reaksi, dan koda ditemukan (1) dari segi fungsi, dominan ditemukan kalimat lengkap, kalimat susun tertib, kalimat tunggal, dan kalimat majemuk, (2) dari segi kategori, fungsi S, P, O, Pel, dan Ket diisi oleh kategori nomina, frase nomina, verba, frase verba, adjektiva, frase adjektiva, numeralia, frase numeralia, preposisi, frase prepoisisi, konjungsi, frase konjungsi (3) dari segi peran, fungsi $S$ berperan sebagai 'pelaku', 'penderita', 'hal', 'pengalam', 'penerima', dan 'terjumlah'. Fungsi $\mathrm{P}$ berperan sebagai 'tindakan/perbuatan', 'keadaan', 'sebab', 'pengenal', 'pemerolehan', 'jumlah', dan 'tempat'. Fungsi O berperan sebagai 'hal', 'penderita', 'penerima', 'hasil, dan 'jumlah'. Fungsi Pel berperan sebagai 'penderita', 'hal', 'tindakan', dan 'keadaan'. Fungsi Ket berperan sebagai 'syarat', 'kemungkinan', 'cara' ,'waktu', 'tempat', 'arah', 'tujuan', 'alat', 'sebab', 'akibat', dan 'kondisional/keadaan'.
\end{abstract}

\section{Kata Kunci: Struktur kalimat, teks anekdot}

\begin{abstract}
Abstrack
The purpose of this study is to describe the sentence structure in anecdotal text in class $X$ high school textbooks (parts of abstraction, orientation, crisis, reaction, and code) that are examined in terms of functions, categories, and the role of each sentence element. This research is a qualitative descriptive. The data in this study are the sentences in the anecdotal text that is sourced from the textbook of high school class X. Data collection techniques in this study were done by using the technique of note. Data were analyzed by using permutation technique and paraphrase technique. The results of this study are from six anecdotal texts, only one text that has anecdotes text structure complete. Five other texts have an incomplete structure. In addition, sentence analysis based on function, category, and role on abstraction, orientation, crisis, reaction, and codes is found (1) in terms of function, dominant found complete sentence, orderly order sentence, single sentence, and compound sentence, (2) ) in terms of categories, the functions S, P, O, Pel,
\end{abstract}


and Ket are filled by the noun, noun, noun, noun phrase, adjective phrase, adjectives, numerical phrases, numerical phrases, prepositions, prepositional phrases, conjunctions, conjunction phrases ) in terms of roles, S functions serve as 'doers', 'sufferers', 'things', 'experiences', 'recipients', and 'totals'. The P function acts as 'action / action', 'state', 'cause', 'identifier', 'gain', 'number', and 'place'. Function $O$ acts as' thing ',' sufferer ',' receiver ',' result, and 'sum'. Pel's functions serve as 'sufferers', 'things', 'actions', and 'circumstances'. The Ket function acts as a 'condition', 'possibility', 'way', 'time', 'place', 'direction', 'goal', 'tool', 'cause', 'effect', and 'conditional / state'

\section{Keywords: Sentence structure, anecdotal text}

\section{PENDAHULUAN}

Sintaksis merupakan salah satu kajian linguistik yang mempelajari hubungan kata, frase, klausa, kalimat, dan wacana. Hubungan antar unsur inilah yang membentuk sebuah struktur yang dalam kalimat disebut dengan struktur kalimat. Struktur kalimat merupakan susunan atau pola tertentu yang membangun sebuah kalimat yang lengkap/selesai.

Dalam sebuah teks atau wacana tulis, pola struktur fungsi-fungsi sintaksis yang muncul antara kalimat satu dengan kalimat lain sangat beragam. Hal ini membentuk berbagai pola struktur kalimat, seperti pola Subjek-Predikat (S-P), Subjek-PredikatObjek (S-P-O), Subjek-Predikat-Pelengkap (S-P-Pel), Subjek-Predikat-Keterangan (S-PKet), Subjek-Predikat-Objek-Keterangan (SP-O-Ket), dan Subjek-Predikat-PelengkapKeterangan (S-P-Pel-Ket) (Achmad, 2012:168-172).

Struktur kalimat dapat ditemui dan dianalisis dalam berbagai teks/wacana. Salah satunya dalam buku-buku teks yang digunakan di sekolah. Hal ini dikarenakan pembelajaran Bahasa Indonesia pada kurikulum 2013 yang berlaku saat ini adalah pembelajaran berbasis teks. Bahkan dalam silabus terbaru yang dikeluarkan oleh Kementerian Pendidikan dan Kebudayaan (Kemendikbud) tahun 2016, khususnya silabus untuk kelas $X$ saja ada lima teks yang harus dipelajari yang meliputi teks laporan hasil observasi, teks eksposisi, teks anekdot, teks cerita rakyat (hikayat), dan teks negosiasi.

Dalam penelitian ini, penulis lebih terfokus pada teks anekdot, yaitu mendeksripsikan struktur kalimat dalam teks anekdot pada buku teks SMA kelas $X$ pada bagian abstraksi, orientasi, krisis, reaksi, dan koda. Teks anekdot merupakan teks berupa cerita, kisah, atau percakapan singkat yang mengandung unsur kelucuan atau humor (Kosasih, 2014:3). Kelucuan dalam anekdot tidak hanya sekedar mengundang tawa, namun mengajak untuk merenungkan suatu kebenaran. Kebenaran di sini biasanya berupa kritik yang berkaitan dengan isu kehidupan orang-orang penting atau terkenal yang sebenarnya. Kejadian nyata ini kemudian dijadikan dasar cerita lucu dengan menambahkan unsur rekaan, sehingga kritik yang disampaikan pun tidak terkesan kasar dan menyakiti (Kemendikbud, 2016:81). Hal inilah yang membedakan antara teks anekdot dengan teks cerita lucu yang lain.

Menurut Kosasih (2014:5-6), anekdot juga memiliki struktur teks yang membedakannya dengan teks-teks lain, yaitu abstraksi, orientasi, krisis, reaksi, dan koda. Abstraksi merupakan pendahuluan yang menyatakan latar belakang atau gambaran umum mengenai isi teks. Orientasi merupakan bagian cerita yang mengarah pada terjadinya suatu krisis, konflik, atau peristiwa utama. Krisis atau komplikasi merupakan bagian dari inti 
peristiwa suatu anekdot yang berisi kekonyolan yang menggelitik dan mengundang tawa. Reaksi merupakan tanggapan atas krisis yang dinyatakan sebelumnya. Reaksi di sini dapat berupa sikap mencela atau menertawakan. Koda merupakan penutup atau kesimpulan sebagai pertanda berakhirnya suatu cerita. Dapat berupa persetujuan, komentar, ataupun penjelasan atas maksud dari cerita yang dipaparkan sebelumnya.

Teks anekdot yang mempunyai lima unsur tersebut merupakan teks yang mempunyai unsur sempurna. Terkadang terdapat teks anekdot yang unsurnya tidak sempurna. Namun, sebuah cerita anekdot minimal terdiri dari pendahulaun (orientasi), konflik (krisis), dan penutup (reaksi) (Yustinah, 2016:59). Berkaitan dengan hal tersebut, penulis akan menganalisis teks anekdot baik yang strukturnya lengkap maupun tidak yang terdapat dalam buku teks. Khususnya menganalisis struktur setiap kalimat dalam setiap bagian teks anekdot tersebut.

Analisis struktur kalimat dalam teks anekdot tersebut akan dilakukan berdasarkan fungsi, kategori, dan peran setiap unsur kalimat. Ketiga aspek tersebut merupakan satu kesatuan yang saling berkaitan. Berdasarkan fungsi, akan dibahas berdasarkan struktur intern, berdasarkan urutan unsur-unsur klausa dalam kalimat, dan berdasarkan bentuk. Berdasarkan struktur internnya, kalimat dapat dibedakan menjadi kalimat lengkap, dan kalimat tidak lengkap. Menurut Haryanta (2012:110), kalimat lengkap merupakan kalimat yang mempunyai segala unsur yang paling sering dipakai dalam suatu bahasa, seperti kalimat yang mengandung subjek dan predikat. Kalimat tidak lengkap merupakan kalimat yang tidak mengandung unsur subjek dan atau predikat (Sumadi, 2009:166).

Berdasarkan urutan unsur-unsur klausa dalam kalimat, kalimat dapat dibedakan menjadi kalimat susun tertib dan kalimat susun balik. Kalimat susun tertib merupakan kalimat yang S-nya mendahului atau berada di depan unsur $P$, sedangkan kalimat susun balik merupakan Kalimat susub balik (inversi) merupakan kalimat yang P-nya mendahului atau berada di depan unsur $S$ (Sumadi, 2008:167).

Berdasarkan bentuk, kalimat dapat dibedakan menjadi kalimat tunggal dan kalimat majemuk. Kalimat tunggal merupakan kalimat hanya mempunyai satu subjek dan satu predikat (Arifin dan Junaiyah, 2008:56). Hal ini sejalan dengan apa yang dinyatakan oleh Alwi (2001:20) bahwa kalimat tunggal adalah kalimat yang hanya terdiri atas satu klausa. Di samping subjek dan predikat, di dalam kalimat tunggal juga terdapat objek dan/atau pelengkap serta keterangan. subjek, predikat, objek, pelengkap, dan keterangan disebut juga dengan unsur kalimat. Sedangkan kalimat majemuk merupakan kalimat yang terdiri dari beberapa klausa. Kalimat majemuk dapat dibedakan menjadi kalimat majemuk setara, kalimat majemuk bertingkat, dan kalimat majemuk taksetara rapatan, dan kalimat majemuk campuran.

Kalimat Majemuk setara merupakan kalimat majemuk yang terdiri atas dua klausa yang unsur-unsurnya sederajat atau setara (Alwi, 2001:24). Artinya, unsur yang satu tidak lebih tinggi atau lebih rendah dari unsur yang lainnya. Masing-masing unsur yang membentuk kalimat majemuk itu dapat berdiri sendiri. Biasanya kalimat majemuk setara ini ditandai dengan kata hubung dan dan serta yang disebut dengan kalimat majemuk setara menggabungkan. Ditandai kata hubung tetapi dan melainkan disebut dengan kalimat majemuk setara mempertentangkan. Dintadai kata penghubung atau disebut dengan kalimat majemuk setara memilih. Ditandai kata 
penghubung bahkan disebut kalimat majemuk perwatasan. Ditandai kata penghubung kemudian dan lalu disebut dengan kalimat majemuk setara perurutan waktu.

Kalimat majemuk tak setara merupakan kalimat majemuk yang terdiri atas klausa inti dan klausa tambahan. Demikian pula Arifin dan Junaiyah (2008:56) menyebutnya dengan unsur induk kalimat dan anak kalimat. Klausa inti atau induk kalimat merupakan inti dari gagasan, sedangkan klausa tambahan atau anak kalimat merupakan gagasan yang dipertalikan kepada gagasan induk kalimat. Berkaitan dengan penggunaan istilah klausa pada kalimat majemuk bertingkat, dalam penelitian ini penulis menggunakan istilah klausa inti dan klausa tambahan.

Kalimat majemuk taksetara rapatan atau kalimat majemuk bertingkat dapat juga dirapatkan jika terdapat unsur subjek yang sama (Arifin dan Junaiyah, 2008:61). Jadi, dalam satu kalimat majemuk unsur subjeknya sama sehingga subjek hanya hadir pada salah satu klausa, dan dilesapkan pada klausa lainnya. Berikut bagan kalimat majemuk taksetara rapatan. Dalam kalimat maejmuk taksetara rapatan, ada beberapa kalimat yang berhemat dengan kata-kata (tidak menggunakan penanda antara klausa inti dan klausa tambahan (Arifin dan Junaiyah, 2008:65). Jadi, dalam kalimat antara klausa inti dan klausa tambahan terkadang hanya ditandai dengan tanda baca koma (,). Kalimat majemuk campuran merupakan kalimat majemuk yang terdiri atas kalimat majemuk setara dan kalimat majemuk taksetara (kalimat majemuk bertingkat (Arifin dan Junaiyah, 2008:66).

\section{METODE}

Metode yang digunakan dalam penelitian ini adalah metode deskriptif kualitatif. Metode deskriptif adalah metode penelitian yang dilakukan guna membuat pencandraan atau deskripsi secara sistemis, faktual, dan akurat mengenai situasi-siatuasi/kejadiankejadian, fakta-fakta, dan fenomena yang terjadi pada masa sekarang ketika penelitian sedang dilaksanakan (Susetyo, 2015:11). Oleh karena itu, penelitian deksriptif kualitatif merupakan suatu penelitian yang dilakukan guna membuat suatu penggambaran rinci mengenai suatu objek tertentu yang dilakukan secara sistematis, faktual, dan akurat (data asli dan sesaui dengan apa adanya). Penelitian ini berbentuk deskriptif karena mendeskripsikan struktur kalimat dalam teks anekdot pada buku teks SMA kelas X.

Dalam penelitian ini penulis melakukan pengumpulan data dengan cara mencatat data berupa kalimat-kalimat yang terdapat dalam teks anekdot pada buku teks SMA kelas $X$ di kartu data yang telah disiapkan. Kemudian data dianalisis dengan menggunakan dua teknik, yaitu teknik permutasi dan teknik parafrase. Teknik permutasi digunakan untuk melakukan pemindahan unsur dengan tujuan melakukan pengujian terhadap unsur dalam sebuah kalimat. Dalam hal ini, hanya unsur yang menduduki fungsi keterangan yang dapat dipindah-pindah (Djajasudarma, 1993:15). Sedangakn teknik parafrase merupakan suatu teknik pengungkapan kembali suatu tuturan dari sebuah tingkatan atau macam bahasa menjadi yang lain dengan tidak mengubah arti, atau penguraian kembali suatu kalimat dalam bentuk yang lain dengan maksud untuk menjelaskan makna yang tersembunyi (Arifin dan Junaiyah, 2008:1617; Djajasudarma, 1993:16) agar analisis peran setiap unsurnya dapat dibuktikan.

\section{HASIL DAN PEMBAHASAN \\ Hasil}

Teks anekdot yang terdapat pada buku teks Bahasa Indonesia SMA kelas $X$ yang diterbitkan oleh Kemendikbud edisi 
revisi 2016, berjumlah enam buah teks anekdot. Dari keenam teks tersebut, hanya satu teks yang memiliki struktur teks anekdot lengkap, yaitu teks 5 yang terdiri atas unsur/bagian abstraksi, orientasi, krisis, reaksi, dan koda. Lima teks lain memiliki struktur tidak lengkap, yaitu satu teks terdiri dari bagian abstraksi, orientasi, krisis, dan reaksi (Teks 1); tiga teks terdiri dari bagian abstraksi, orientasi, krisis (Teks 2, 3, dan 4); dan satu teks hanya terdiri atas bagian orientasi dan krisis (Teks 6). Dari uraian tersebut diketahui bahwa bagian orientasi dan krisis ada pada setiap teks. Bagian krisis dalam teks anekdot merupakan bagian inti dari suatu teks anekdot.

Kalimat yang diperoleh dari keenam teks anekdot berjumlah 84 kalimat. Bagian abstraksi terdiri atas 9 kalimat. Bagian orientasi terdiri atas 49 kalimat. Bagian krisis terdiri atas 21 kalimat. Bagian reaksi terdiri atas 4 kalimat. Bagian koda terdiri atas 1 kalimat.

\section{Pembahasan}

Berikut analisis unsur-unsur klausa dalam struktur kalimat teks anekdot bagian abstraksi, orientasi, krisis, reaksi, dan koda pada buku teks SMA kelas $X$ yang dikaji berdasarkan fungsi, kategori dan peran.

\section{Bagian Abstraksi Teks Anekdot}

Berdasarkan data, pada bagian asbtraksi dari enam teks anekdot ada 5 teks yang memiliki bagian abstraksi. Dari 5 teks tersebut terdapat 9 kalimat dengan 5 ragam pola kalimat tunggal yang meliputi pola S-P-Pel, S-P-Ket, Ket-S-P, S-P-O-Pel, SP-O-Ket-O, dan 3 ragam pola kalimat majemuk, meliputi pola S-S-P-O-Ket, S-PPel, dan pola S-P-O-S-P-O Konj-S-P-Ket-Konj-P.

Berdasarkan segi fungsi, dilihat dari struktur internnya seluruh kalimat berupa kalimat lengkap. Dilihat dari urutan fungsi unsur-unsur dalam kalimat, berupa kalimat susun tertib/susun biasa dan kalimat susun balik. Dilihat dari bentuknya seluruh kalimat terdiri atas kalimat tunggal.

Dari segi kategori unsur-unsur klausa dalam struktur kalimat, fungsi S diisi oleh kategori frase nomina. Fungsi $P$ diisi oleh kategori frase verba. Fungsi $O$ diisi oleh kategori frase nomina dan frase numeralia. Fungsi Pel diisi oleh kategoriverba/frase verba dan frase nomina. Fungsi Ket diisi oleh kategori frase nomina, frase preposisi, dan frase konjungsi.

Berdasarkan segi peran unsurunsur klausa dalam struktur kalimat pada bagian abstraksi peran pengisi $S$, berperan sebagai 'pelaku'. Fungsi P berperan sebagai 'tindakan/perbuatan'. Fungsi $O$ berperan sebagai 'hal', dan 'penderita'. Fungsi Pel berperan sebagai 'keadaan', 'tindakan', 'penderita', dan 'hal'. Fungsi Ket berperan sebagai 'penerima', 'tempat', dan 'tujuan'.

Contoh analisis:

(1) Di kantin sebuah universitas, Udin dan Tono dua orang mahasiswa sedang berbincang-bincang. (VA/4/t 1/ k 1)

Kalimat (1) merupakan kalimat yang berpola Ket-S-P. Unsur di kantin sebuah universitas menduduki fungsi Ket, unsur Udin dan Tono dua orang mahasiswa menduduki fungsi $\mathrm{S}$, dan unsur sedang berbincang-bincang menduduki fungsi $P$.

Fungsi Ket (di kantin sebuah universitas) diisi oleh kategori FPrep, karena ditandai dengan kata depan $d i$. Fungsi S diisi oleh kategori FN, karena frase Udin dan Tono dua orang mahasiswa mengandung kelas kata nomina yaitu nomina berupa orang (Udin dan Tono). Selain itu, fungsi $S$ berkategori FN juga dapat dibuktikan dengan cara menggabungkannya dengan kata bukan (sebagai salah satu ciri N), menjadi bukan 
Udin dan Tono dua orang mahasiswa. Frasa tersebut berterima, sehingga fungsi $S$ berkategori $\mathrm{N}$ terbukti benar. Fungsi $\mathrm{P}$ diisi oleh kategori FV, karena ditandai dengan kata depan sedang yang menunjukkan suatu kegiatan.

Fungsi Ket (di kantin sebuah universitas) berperan sebagai 'tempat' karena ditandai dengan kata depan 'di' yang menunjukkan suatu tempat. Fungsi $\mathrm{S}$ (Udin dan Tono dua orang mahasiswa), berperan sebagai 'pelaku' karena melakukan apa yang ada pada $\mathrm{P}$. Fungsi $\mathrm{P}$ (sedang berbincang-bincang) berperan sebagai 'tindakan/perbuatan', yaitu tindakan/perbuatan yang sedang dilakukan oleh S sebagai 'pelaku'.

Unsur di kantin sebuah universitas menduduki fungsi Ket, karena posisinya dapat dipindah-pindah. Seperti kalimat berikut.

[1a] Udin dan Tono dua orang mahasiswa, di kantin sebuah universitas sedang berbincang-bincang.

[1b] Udin dan Tono dua orang mahasiswa sedang berbincang-bincang, di kantin sebuah universitas.

Kalimat [1a] dan [1b] merupakan permutasi kalimat [1]. Meskipun kalimat [1] unsur Ket mengalami perpindahan letak menjadi kalimat [1a] dan [1b], namun informasi yang terkandung di dalamnya tetap sama, sehingga fungsi Ket pada kalimat [1] teruji kebenarannya.

Berdasarkan kelengkapan unsur $\mathrm{S}$ dan $P$, kalimat (1) termasuk kalimat lengkap. Jika dilihat dari susunan $\mathrm{S}$ dan $\mathrm{P}$ merupakan kalimat susun tertib/susun biasa. Kemudian, berdasarkan bentuknya disebut sebagai kalimat tunggal karena hanya terdiri atas satu klausa.

Dari uraian tersebut, agar lebih jelas dapat diperhatikan tabel 1 berikut.
Tabel 1

\begin{tabular}{|l|c|c|c|}
\hline Kalimat & $\begin{array}{l}\text { di kantin } \\
\text { sebuah } \\
\text { universitas }\end{array}$ & $\begin{array}{l}\text { Udin dan } \\
\text { Tono dua } \\
\text { orang } \\
\text { mahasiswa }\end{array}$ & $\begin{array}{l}\text { sedang } \\
\text { berbincang- } \\
\text { bincang }\end{array}$ \\
\hline Fungsi & Ket & S & P \\
\hline Kategori & Fprep & FN & FV \\
\hline Peran & Tempat & Pelaku & $\begin{array}{l}\text { Tindakan/ } \\
\text { Perbuatan }\end{array}$ \\
\hline
\end{tabular}

\section{Bagian Orientasi}

Berdasarkan data, seluruh teks memiliki bagian orientasi. Bagian orientasi tersebut terdiri atas 49 kalimat dengan 5 ragam pola kalimat tidak lengkap yang meliputi pola (S-P-Pel)-Ket, (S-P-O)-Ket-Ket, (S-P)-O, (S)-P, (S)-P-Pel, 9 ragam pola kalimat tunggal yang meliputi pola $S-P, S-P-$ O, S-P-Pel, Ket-Konj-S-P, Ket-S-P-Ket, S-P-OKet, Ket-S-P-O, Ket-S-P-O-Ket, S-P-Pel-Ket.

Berdasarkan segi fungsi, dilihat dari struktur internnya, seluruh kalimat berupa kalimat lengkap. Dilihat dari urutan $\mathrm{S}$ dan $P$, seluruh kalimat berupa kalimat susun tertib/susun biasa. Dilihat dari bentuknya terdiri atas kalimat tunggal dan kalimat majemuk bertingkat.

Berdasarkan segi kategori pengisi fungsi-fungsi yang menduduki unsur klausa dalam struktur kalimat pada bagian orientasi, fungsi $\mathrm{S}$ diisi oleh kategori nomina/frase nomina. Fungsi $P$ diisi oleh kategori verba/frase verba, kategori nomina/frase nomina, frase adjektiva, frase numeralia, dan frase preposisi. Fungsi $O$ diisi oleh kategori nomina/frase nomina, frase adjektiva, dan frase numeralia. Fungsi Pel diisi oleh kategori frase preposisi, nomina/frase nomina, verba/frase verba, frase konjungsi, dan frase adjektiva. Fungsi Ket diisi oleh kategori frase preposisi, nomina/frase nomina, frase adverbial, dan frase adjektiva.

Berdasarkan segi peran setiap unsur kalimat, fungsi $\mathbf{S}$ berperan 'pelaku', 'hal', 'penderita', 'dikenal', 'penerima', dan 'terjumlah'. Fungsi $P$ berperan sebagai 
'tindakan/perbuatan', 'keadaan', 'sebab', 'pengenal', 'pemerolehan', 'jumlah', dan 'tempat'. Fungsi O berperan sebagai 'hal', 'penderita', 'hasil, dan 'jumlah'. Fungsi Pel berperan sebagai 'penderita', 'hal', 'tindakan', dan 'keadaan'. Fungsi Ket berperan sebagai 'cara', 'tujuan', 'akibat', 'sebab', 'syarat', 'kondisional', 'waktu', 'tempat', 'arah', 'alat', 'penderita', 'perbandingan'.

Contoh analisis:

(2) Itulah yang ia lakukan terus sampai ia terlatih membalik-balik halaman buku itu. (VB/41/t 2/k 25)

Kalimat (2) merupakan kalimat majemuk bertingkat. Klausa inti terdiri atas unsur S-P-Pel, sedangkan klausa tambahan yaitu klausa tambahan pengganti/pengisi fungsi Ket, berpola S-P-O.

Pada klausa inti, unsur itulah yang ia lakukan menduduki fungsi S. unsur terus menduduki fungsi P. Unsur sampai ia terlatih membalik-balik halaman buku itu menduduki fungsi Ket.

Pada klausa tambahan pengganti atau pengisi fungsi Ket, unsur ia menduduki fungsi $\mathrm{S}$. Unsur terlatih membalik-balik menduduki fungsi $\mathrm{P}$, dan unsur halaman buku itu menduduki fungsi O.

Pada klausa inti, fungsi S (itulah yang ia lakukan) diisi oleh kategori FN karena mengandung nomina yaitu kata ganti orang kedua (ia). Fungsi $\mathrm{P}$ (terus) diisi oleh kategori $\mathrm{V}$, karena kata terus termasuk dalam kelas kata verba. Fungsi Ket (sampai ia terlatih membalik-balik halaman buku itu) diisi oleh kategori FAdj karena terdapat adjektiva terlatih. Fungsi S berperan sebagai 'sebab', fungsi $P$ berperan sebagai 'tindakan/perbuatan', dan fungsi Ket berperan sebagai 'akibat'.

Pada klausa tambahan pengganti/pengisi fungsi Ket, fungsi S (ia) diisi oleh kategori $\mathrm{N}$, karena berupa kata ganti orang kedua. Fungsi $\mathrm{P}$ (terlatih membalik-balik) diisi oleh kategori FV karena dapat dinegasikan dengan kata tidak sebagai salah satu ciri kelas kata verba, menjadi tidak terlatih membalikbalik. Frase tersebut berterima, sehingga fungsi $P$ berkategori FV dapat dibuktikan kebenarannya. Fungsi O (halaman buku itu) diisi oleh kategori FN, karena mengandung nomina, yaitu buku. Selain itu, juga dapat dinegasikan dengan kata bukan sebagai salah satu ciri kelas kata nomina, menjadi bukan halaman buku itu. Frase tersebut berterima, sehingga fungsi O diisi oleh kategori FN dapat dibuktikan kebenarannya. Fungsi $\mathrm{S}$ berperan sebagai 'pelaku', fungsi $\mathrm{P}$ berperan sebagai 'tindakan/perbuatan', dan fungsi $O$ berperan sebagai 'penderita'.

Berdasarkan uraian tersebut, agar lebih jelas dapat diperhatikan tabel 2 dan 3 berikut.

Tabel 2. Kluasa Inti

\begin{tabular}{lccc}
\hline Kalimat & $\begin{array}{l}\text { itulah } \\
\text { yang ia } \\
\text { lakukan }\end{array}$ & terus & $\begin{array}{l}\text { sampai ia terla } \\
\text { tih membalik- } \\
\text { balik halaman } \\
\text { buku itu }\end{array}$ \\
\hline Fungsi & S & P & Ket \\
\hline $\begin{array}{l}\text { Kate } \\
\text { gori }\end{array}$ & FN & $\mathrm{V}$ & FAdj \\
\hline Peran & Sebab & Tindakan & $\begin{array}{l}\text { Aki } \\
\text { bat }\end{array}$
\end{tabular}

Tabel 3. Klausa tambahan pengganti/ pengisi fungsi Ket

\begin{tabular}{lccc}
\hline Kalimat & ia & $\begin{array}{l}\text { terlatih } \\
\text { membalik- } \\
\text { balik }\end{array}$ & $\begin{array}{c}\text { halaman buku } \\
\text { itu }\end{array}$ \\
\hline Fungsi & $\mathrm{S}$ & $\mathrm{P}$ & $\mathrm{O}$ \\
\hline Kategori & $\mathrm{N}$ & $\mathrm{FV}$ & $\mathrm{FN}$ \\
\hline Peran & Pelaku & $\begin{array}{l}\text { Tindakan/ } \\
\text { Perbuatan }\end{array}$ & Penderita
\end{tabular}

\section{Bagian Krisis}

Struktur kalimat dalam teks anekdot, pada bagian krisis meliputi sebagai berikut.

a. Pada teks 1 terdiri atas 2 kalimat dengan satu pola kalimat tidak 
lengkap dan satu pola kalimat majemuk. Satu pola kalimat tidak lengkap, yaitu pola $\mathrm{O}$, dan satu pola kalimat majemuk berpola Ket-(S)-PPel

$\overline{S-P-O}$

b. Pada teks 2 terdiri atas 3 kalimat majemuk bertingkat, meliputi pola $\mathrm{S}$ P-O-P-S, S-P- $\frac{\text { Pel }}{\text { S-P-O-Pel }}$

dan pola Ket-P-Pel-Ket-P-S-Ket.

c. Pada teks 3 terdiri atas 1 pola kalimat tidak lengkap berpola (S)-P-Pel, dan 1 kalimat tunggal berpola S-P.

d. Pada teks 4 terdiri atas 3 pola kalimat tidak lengkap, yaitu pola S-Ket, Ket, dan pola Ket-(S)-P-O. Satu pola kalimat lengkap, yaitu pola S-P-Ket, dan 2 pola kalimat majemuk yang berpola S- Pel, dan S-Ket-P-O-S. S-O-Ket-Ket

e. Pada teks 5 terdiri atas 2 kalimat tidak lengkap dengan pola (S)-P, dan pola (S)-P-O-Pel-Ket. Satu kalimat tunggal dengan pola S-P-Ket-O, dan satu

kalimat majemuk dengan pola S-P$\frac{\text { Ket . }}{\text { S-P-Ket }}$

f. Pada teks 6 terdiri atas 2 kalimat majemuk. Terdiri atas pola S-P- $\frac{\mathrm{Pel} \text {, }}{\mathrm{S}-\mathrm{P}-\mathrm{O}}$ dan pola S-P-Konj-(S)-P-Pel-S-P-Pel

Dari uraian ragam pola pada bagian krisis atau inti teks anekdot tersebut dari teks 1 sampai teks 6 , dapat dinyatakan bahwa pola kalimat yang ditemukan sama dengan pola kalimat pada umumnya.

Berdasarkan segi fungsi, dilihat dari struktur internnya, dari 6 teks tersebut ada kalimat yang berupa kalimat lengkap dan tidak lengkap. Dilihat dari urutan $\mathrm{S}$ dan $\mathrm{P}$, seluruh kalimat berupa kalimat susun tertib/susun biasa. Dilihat dari bentuknya terdiri atas kalimat tunggal dan kalimat majemuk bertingkat.

Berdasarkan segi kategori pengisi fungsi-fungsi yang menduduki unsur klausa dalam struktur kalimat pada bagian krisis fungsi $S$ diisi oleh kategori N/FN. Fungsi $P$ diisi oleh kategori verba/frase verba dan frase preposisi, dan nomina. Fungsi $O$ diisi oleh kategori nomina, dan frase nomina. Fungsi Pel diisi oleh kategori nomina, verba, dan frase konjungsi. Fungsi Ket diisi oleh kategori frase konjungsi dan frase adjektiva, nomina, dan verba.

Berdasarkan segi peran setiap unsur kalimat, fungsi $\mathbf{S}$ berperan sebagai 'pelaku', 'hal', 'objektif', dan 'penerima', dan 'penderita'. Fungsi $P$ berperan sebagai 'tindakan/ perbuatan', 'tempat', 'keadaan', dan 'pemerolehan'. Fungsi $O$ berperan sebagai 'ha', 'penderita', dan 'pelaku', dan 'keadaan'. Fungsi Pel berperan sebagai 'penderita','keadaan', 'hal', dan 'tindakan'. Fungsi Ket berperan sebagai 'asal', 'waktu', 'tempat', 'cara', 'tujuan', 'perbandingan', dan 'sebab'.

Contoh analisis:

(3) Dari Yogya, Mas. (VC/1/t 4/k 12)

Kalimat (3) merupakan kalimat tidak lengkap. Disebut kalimat tidak lengkap, karena hanya terdiri dari dua unsur. Unsur dari Yogya yang menduduki fungsi Ket, berkategori FPrep karena ditandai dengan kata depan dari, dan berperan sebagai 'asal' dan unsur Mas yang berperan sebagai interjeksi.

Unsur dari Yogya ini menduduki fungsi Ket, karena mengingat bahwa kalimat (3) merupakan jawaban dari pertanyaan pada kalimat sebelumnya yaitu "Emang nangkanya impor dari mana?". Oleh karena itu, jawaban lengkap dari pertanyaan ini yaitu "Nangkanya diimpor dari Yogya, Mas.", sehingga unsur 
nangkanya menduduki fungsi $\mathrm{S}$, unsur impor menduduki fungsi $\mathrm{P}$, dan unsur dari Yogya menduduki fungsi Ket. Dengan begitu, unsur dari Yogya menduduki fungsi Ket pada kalimat (3) dapat dibuktikan kebenarannya.

Agar lebih jelas dapat diperhatikan tabel 4 berikut.

Tabel 4

\begin{tabular}{l|c|c}
\hline Kalimat & dari Yogya & Mas \\
\hline Fungsi & Ket & \\
\hline Kategori & FPrep & Inter \\
Peran & jeksi \\
& Asal & \\
\hline
\end{tabular}

\section{Bagian Reaksi}

Berdasarkan data, hanya terdapat 2 teks yang mengandung unsur reaksi. Pada bagian reaksi tersebut terdapat 4 kalimat yang terdiri atas 3 kalimat yang memiliki pola. Tiga kalimat tersebut memiliki ragam pola yang berbeda, yaitu 2 kalimat dengan pola kalimat tunggal yang meliputi pola $\mathrm{S}$ $P$ dan O-S-P, dan satu

kalimat majemuk dengan pola $\mathrm{P}-\mathrm{Ket}$. P-O-Ket

Berdasarkan segi fungsi, dilihat dari struktur internnya seluruh kalimat berupa kalimat lengkap. Dilihat dari urutan $\mathrm{S}$ dan $P$, seluruh kalimat berupa kalimat susun tertib/susun biasa. Dilihat dari bentuknya terdiri atas kalimat tunggal dan kalimat majemuk bertingkat.

Berdasarkan segi kategori unsurunsur kalimat, fungsi $\mathrm{S}$ diisi oleh kategori nomina dan frase nomina. Fungsi $P$ diisi oleh kategori verba, dan frase adjektiva. Fungsi $O$ diisi oleh kategori nomina. Fungsi Ket diisi oleh kategori frase konjungsi.

Berdasarkan segi peran setiap unsur kalimat, pada bagian reaksi fungsi $S$ berperan sebagai 'hal', dan 'pelaku'. Fungsi $P$ berperan sebagai 'keadaan' dan 'tindakan/perbuatan'. Fungsi $O$ berperan sebagai 'penderita'. Fungsi Ket berperan sebagai 'cara'.
Contoh analisis:

(4)Itu illegal. (VD/1/t 5/k 12)

Kalimat (4) merupakan kalimat tunggal berpola S-P. Unsur itu berfungsi sebagai $\mathrm{S}$, berkategori $\mathrm{N}$ karena kata itu termasuk dalam kategori nomina, dan perperan sebagai 'hal'. Unsur illegal berfungsi sebagai $P$, berkategori Adj karena kata illegal termasuk dalam kelas kata sifat, dan berperan sebagai 'keadaan'.

Agar lebih jelas dapat diperhatikan tabel 5 berikut.

Tabel 5

\begin{tabular}{lcc}
\hline Kalimat & itu & ilegal \\
\hline Fungsi & $\mathrm{S}$ & $\mathrm{P}$ \\
\hline Kategori & $\mathrm{N}$ & Adj \\
\hline \multicolumn{1}{c}{ Peran } & Hal & Keadaan \\
\hline
\end{tabular}

\section{Bagian Koda}

Berdasarkan data, hanya ada satu teks yang memiliki unsur koda dan terdapat satu kalimat dengan pola (S)-P. Dari segi fungsi, dilihat dari struktur internnya, hanya terdiri atas satu kalimat tidak lengkap, sehingga dilihat dari urutan unsur $\mathrm{S}$ dan $\mathrm{P}$, dan berdasarkan bentuknya tidak ada kalimat yang berupa kalimat susun tertib, susun balik, kalimat tunggal, maupun kalimat majemuk. Dari segi kategori pengisi fungsi, hanya terdapat fungsi $P$ yang berkategori frase $V$, dan berperan sebagai 'tindakan/perbuatan'.

Contoh analisis:

(5) Hanya bisa pasrah tak berdaya. (Ve/t 5, k 14)

Kalimat (5) merupakan kalimat tidak lengkap yaitu berpola (S)-P. Unsur yang menduduki fungsi $S$ dalam kalimat tersebut dilesapkan. Jika dibuat dalam bentuk lengkapnya, kalimat tersebut menjadi Dia hanya bisa pasrah tak berdaya, sehingga unsur hanya bisa pasrah tak berdaya pada kalimat (5) menduduki 
fungsi $\mathrm{P}$, berkategori $\mathrm{FV}$, dan berperan sebagai 'tindakan/perbuatan'.

Agar lebih jelas dapat diperhatikan tabel 6 berikut.

Tabel 6

\begin{tabular}{lc}
\hline Kalimat & hanya bisa pasrah tak berdaya \\
\hline Fungsi & $\mathrm{P}$ \\
\hline Kategori & $\mathrm{FV}$ \\
\hline Peran & Tindakan/Perbuatan \\
\hline
\end{tabular}

\section{PENUTUP}

\section{Kesimpulan}

Hasil penelitian ini yaitu dari enam teks anekdot, hanya satu teks yang memiliki struktur teks anekdot lengkap. Lima teks lain memiliki struktur tidak lengkap. Selain itu, analasis kalimat berdasarkan fungsi, kategori, dan peran pada bagian abstraksi, orientasi, krisis, reaksi, dan koda ditemukan (1) dari segi fungsi, dominan ditemukan kalimat lengkap, kalimat susun tertib, kalimat tunggal, dan kalimat majemuk, (2) dari segi kategori, fungsi S, P, O, Pel, dan Ket diisi oleh kategori nomina, frase nomina, verba, frase verba, adjektiva, frase adjektiva, numeralia, frase numeralia, preposisi, frase prepoisisi, konjungsi, frase konjungsi (3) dari segi peran, fungsi $S$ berperan sebagai 'pelaku', 'penderita', 'hal', 'pengalam', 'penerima', dan 'terjumlah'. Fungsi $P$ berperan sebagai 'tindakan/perbuatan', 'keadaan', 'sebab', 'pengenal', 'pemerolehan', 'jumlah', dan 'tempat'. Fungsi $O$ berperan sebagai 'hal', 'penderita', 'penerima', 'hasil, dan 'jumlah'. Fungsi Pel berperan sebagai 'penderita', 'hal', 'tindakan', dan 'keadaan'.
Fungsi Ket berperan sebagai 'syarat', 'kemungkinan', 'cara' ,'waktu', 'tempat', 'arah', 'tujuan', 'alat', 'sebab', 'akibat', dan 'kondisional/keadaan'.

\section{DAFTAR PUSTAKA}

Achmad H.P. Sintaksis Bahasa Indonesia. 2012. Tangerang: PT. Pustaka Mandiri.

Alwi, Hasan. 2001. Kalimat. Jakarta: Pusat Bahasa.

Arifin, Zaenal dan Junaiyah. 2008. Sintaksis. Jakarta: PT. Grasindo.

Djajasudarma, Fatimah. 1993. Metode Linguistik: Ancangan Metode Penelitian dan Kajian. Bandung: Penerbit PT. Eresco

Haryanta, Agung Tri. 2012. Kamus Kebahasaan dan Kesusastraan.Surakarta: Aksara Sinergi Media.

Kemendikbud. 2016. Bahasa Indonesia. Jakarta: Kementerian Pendidikan dan Kebudayaan.

Kosasih, E. 2014. Jenis-jenis Teks Analisis Fungsi, Struktur, dan Kaidah serta Langkah Penulisannya. Bandung: Penerbit Yrama Widya.

Sumadi. 2009. Sintaksis Bahasa Indonesia. Malang: Penerbit Asih Asah Asuh.

Susetyo. 2015. Penelitian Kuantitatif dan Penelitian Tindakan Kelas. Bengkulu: Fakultas Keguruan dan Ilmu Pendidikan Universitas Bengkulu.

Yustinah. 2016. Produktif Berbahasa Indonesia untuk SMK/MAK Kelas $X$. Jakarta: Penerbit Erlangga. 